\section{Discussion}

Knowledge of traditional concepts and systems on the part of Western-trained psychiatrists is essential, in particular because of the widespread parallel use of services, as well as the problems experienced with unregulated and sometimes problematic indigenous services. Descriptions of indigenous categories differ from Western ones and need to be understood by all health practitioners. There is a need to improve psychiatric services for the population identified as attending traditional practitioners simultaneously.

\section{References}

Ensink, K. \& Robertson, B. (1996) Indigenous categories of distress and dysfunction in South African Xhosa children and adolescents as described by indigenous healers. Transcultural Psychiatry, 33, 137-172.

Ensink, K. \& Robertson B. (1999) Patient and family experiences of psychiatric services and African indigenous healers. Transcultural Psychiatry, 36, 23-43.

Ensink, K., Leger, P. \& Robertson, B. (1995) Public Sector Mental Health Services in the Western Cape: An Expenditure Review. Working Paper 2. University of Cape Town.

Kleinman, A. (1988) Rethinking Psychiatry: From Cultural Category to Personal Experience. Free Press.

\title{
Nosology and modalities for deciding on the management of patients with psychiatric illness among traditional healers in Lagos, Nigeria
}

\author{
Olufemi Olugbile FRCPsych, ${ }^{1}$ N. P. Zachariah $\mathrm{PhD}^{2}$ and B. Isichei $\mathrm{MSc}^{3}$
}

1Department of Psychiatry, Lagos State University Teaching Hospital, Ikeja, Lagos State, Nigeria, email femi_olugbile@yahoo.com

${ }^{2}$ Department of Psychiatry, Lagos State University Teaching Hospital, Ikeja, Nigeria ${ }^{3}$ Department of Social Welfare, Lagos State University Teaching Hospital, Ikeja, Nigeria

$M$ any patients in Nigeria consult traditional healers before, or in parallel with, modern psychiatric services. Part of the attraction of traditional medicine for the populace, apart from its lower cost and easier accessibility, may lie in its 'cultural' explanatory concepts of the nature and course of mental disorder.

The aims of the present study were to define the understanding of the generality of traditional mental health practitioners in Lagos about the nature and causation of mental disorder, and to obtain explanations of their classificatory systems, treatment approaches and expected outcomes of treatment.

\section{Method}

A gathering of traditional mental health practitioners was arranged, facilitated by the Lagos State Board of Traditional Medicine. In the course of a day-long, free-flowing interaction, a questionnaire was administered to the 15 practitioners present. All 15 completed and returned the questionnaire.

\section{Results}

\section{Aetiological clusters}

The following aetiological clusters emerged:

O cursing/spiritual attack/quest for spiritual power ('Epe', 'Asasi', etc.)

$\mathrm{O}$ ingestion/smoking of drugs of misuse
O diseases of the body (smallpox, chronic disease affecting the brain)

O disturbance of mind ('excessive thinking', 'excessive studying')

o stress-related conditions ('unexpected shock', loss of child or spouse, poverty, etc.)

heredity.

\section{Typology based on observed behaviour}

There were seven thematic clusters of types of behaviour, which were not mutually exclusive:

O withdrawn/silent

O violent

O excessive talking to self

o laughing without reason

O temporary abnormal behaviour ('asinwin')

O sluggish behaviour ('arindin')

O 'ode ori' (typified by a combination of somatic symptoms affecting the head and body).

\section{Treatment modalities employed}

The following types of treatment were often employed in combination:

herbal (the commonest reported intervention)

O incantations

o animal or other sacrifice

body incisions/scarifications

o special diet/nutritional support.

Duration of treatment was generally around 2-6 months. 


\section{Expected treatment outcome}

Complete cure (irrespective of typology) was the outcome claimed by the majority of respondents (86.6\%). The achievement of only symptom relief and the possibility of relapse were acknowledged by a minority (13.4\%).

\section{Rehabilitation issues and stigma}

Participants were asked whether the educational or professional aspirations of treated patients should be limited. Just over a quarter agreed (27\%) and the remainder said no (73\%).

\section{Discussion}

There is a need for health planners, researchers and the practitioners of modern medical therapies in Africa to develop some kind of a relationship with traditional healers. The following is a broad classification of the attitudes of medical practitioners to traditional healers:

O Curiosity (traditional practitioners are viewed as creatures from another planet, dressing in strange attires and performing bizarre rituals) (Jilek \& Jilek, 1967).

o Grudging acknowledgement of traditional medicine as a temporary nuisance which will disappear as modern services become more generally available.

- Acknowledgement of traditional medicine as a reality which may be 'elevated' by contact with modern concepts and practices (Adelekan \& Makanjuola, 2001).

O Recognition of it as a distinct entity that deserves to be respected and explored without preconception (Makanjuola, 1987).

What impact, if any, is traditional mental healthcare having even now on the members of society in low- and middleincome countries, where it is most prevalent? Haliburton (2004) analysed the follow-up data of patients in India who patronised the three recognised systems of mental healthcare in the country: Ayurvedic (indigenous), 'allopathic' (Western psychiatry) and 'religious healing'. He found that patrons of all three showed improvement on follow-up. Some people found one therapy model more useful than the others. Many used more than one model. The researcher suggested that the availability of such diverse options increases the chances that any one patient will find a mode of treatment that will suit their needs. He postulated that this may lead to better outcomes for psychotic illness in that part of the world than in higher-income countries.

How is the profession of psychiatry to relate to traditional mental healthcare? By studiously ignoring it, hoping it will die out? By acknowledging it and seeking to 'educate it' about modern medical concepts? Or by an uncritical acceptance of all its concepts and claims?

Unfortunately, there is great variety in thinking and practice among traditional practitioners. There is little standardisation, and no corpus of belief or knowledge that is accepted by everyone.

\section{Should traditional medicine be taught in medical schools?}

The College of Medicine, Usman Dan Dodio University, Sokoto, in northern Nigeria, some years ago introduced a programme whereby 90 hours of instruction in traditional medicine was added to the undergraduate medical course. The justification was that since the patients that the students will treat when they become doctors will see traditional healers anyway, it is appropriate that the students get to know what traditional medicine is all about.

\section{Conclusions and recommendations}

Psychiatrists in Africa must recognise the existence of traditional mental healthcare and initiate dialogue with it. Such dialogue has been proposed or is actually in process in Malaysia, India and China. Some of the immediate gains of such dialogue would be to drive forward the pace of standardisation and codification of the conceptual framework, nosology and practice of traditional medicine. It would also help to expunge the most unsavoury elements, such as cruel physical restraint and punishments, from the practice of traditional healers. It would help to bring in such modern ideas as the need to respect patients' legal rights to humane and decent treatment. It would create a platform for comparative studies of the efficacy and outcome of interventions in both the short and the long term. An added bonus may be the discovery of new drugs from 'age old' remedies.

A first step in the organisation of such a process would be for governments to set up boards, such as the one in Lagos, with the legal authority to register and control the practice of traditional medicine in their area of authority.

\section{Acknowledgements}

We are grateful to Dr Bunmi Omoseindemi, Chairman, Lagos State Traditional Medicine Board, and all the staff of the Board for their assistance with the research.

\section{References}

Adelekan, M. L. \& Makanjuola, A. B. (2001) Traditional mental health in Kwara State, Nigeria. East African Medical Journal, 78, 190-196.

Haliburton, M. (2004) Finding a fit: psychiatric pluralism in South India and its implication for WHO studies of mental disorder. Transcultural Psychiatry, 41, 80-98.

Jilek, W. G. \& Jilek L. M. (1967) Psychiatric concepts and conditions in the Wapogoro tribe in Tangayika. Bibliotheca Psychiatrica et Neurologica, 132, 205-228.

Makanjuola, R. O. (1987) Yoruba traditional healers in psychiatry healers' concepts of the nature and aetiology of mental disorders. African Journal of Medical Science, 16, 53-59.

Correspondence regarding articles published in International Psychiatry is always welcome. Letters of no more than 500 words should be sent to the Correspondence Editor, Amit Malik MRCPsych, Consultant Psychiatrist, Hampshire Partnership NHS Trust, emailip@rcpsych.ac.uk 